University of Wollongong

Research Online

Australian Institute for Innovative Materials -

Papers

Australian Institute for Innovative Materials

$1-1-2019$

Selenium@Hollow mesoporous carbon composites for high-rate and longcycling lithium/sodium-ion batteries

Pan Xue

Yanjun Zhai

Nana Wang

University of Wollongong, nw415@uowmail.edu.au

Yaohui Zhang

Zhenxiao Lu

See next page for additional authors

Follow this and additional works at: https://ro.uow.edu.au/aiimpapers

Part of the Engineering Commons, and the Physical Sciences and Mathematics Commons

Research Online is the open access institutional repository for the University of Wollongong. For further information contact the UOW Library: research-pubs@uow.edu.au 


\title{
Selenium@Hollow mesoporous carbon composites for high-rate and long-cycling lithium/sodium-ion batteries
}

\author{
Abstract \\ (C) 2019 Elsevier B.V. Selenium (Se) is a prospective candidate of electrode material for high-energy \\ batteries. However, the low Se loading, volumetric expansion and polyselenide shuttling between cathode \\ and anode are major factors to limit further development. To overcome above issues, the hollow carbon \\ structure with interconnected mesopores is used to confine Se composite via a facile annealing \\ treatment route. The Se/HMCS electrode exhibits excellent performance, including a long cycle life (710 \\ $\mathrm{mA} \mathrm{h} \mathrm{g-1} \mathrm{at} \mathrm{the} \mathrm{800th} \mathrm{cycle} \mathrm{at} 0.5 \mathrm{~A} \mathrm{~g}-1$ for LIBs and $291 \mathrm{~mA} \mathrm{~h} \mathrm{~g}-1$ at the 1500 th cycle at $0.5 \mathrm{~A} \mathrm{~g}-1$ for \\ SIBs). When coupled with LiCoO2 and Na3V2(PO4)3/C in full cells, this electrode also exhibits superior

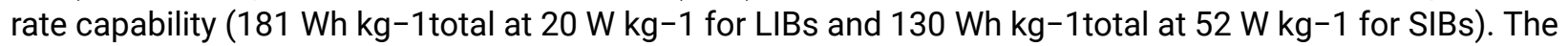 \\ excellent electrochemical performance is attributed to the unique hollow structure of HMCS and a large \\ amount of Se encapsulated within mesoporous, which not only promote electronic/ionic transport but \\ also provide additional buffer space to adjust the volumetric expansion of Se and polyselenide during \\ long cycling. This facile and novelty strategy could be easily extended to other materials with low \\ electronic conductivity for advanced energy storage systems.

\section{Disciplines} \\ Engineering | Physical Sciences and Mathematics

\section{Publication Details} \\ Xue, P., Zhai, Y., Wang, N., Zhang, Y., Lu, Z., Liu, Y., Bai, Z., Han, B., Zou, G. \& Dou, S. (2019). \\ Selenium@Hollow mesoporous carbon composites for high-rate and long-cycling lithium/sodium-ion \\ batteries. Chemical Engineering Journal,

\section{Authors} \\ Pan Xue, Yanjun Zhai, Nana Wang, Yaohui Zhang, Zhenxiao Lu, Yuanlin Liu, Zhongchao Bai, Baokun Han, \\ Guifu Zou, and Shi Xue Dou
}




\section{Selenium@Hollow Mesoporous Carbon Composites for High-Rate and Long-Cycling Lithium/Sodium-Ion Batteries}

Pan Xue ${ }^{a, d}$, Yanjun Zhai ${ }^{b}$, Nana Wang ${ }^{c}$, Yaohui Zhang ${ }^{d}$, Zhenxiao Lu ${ }^{d}$, Yuanlin Liu ${ }^{d}$, Zhongchao Bai ${ }^{a, d^{*}}$, Baokun Han ${ }^{a^{*}}$, Guifu Zou ${ }^{a, e^{*}}$, Shixue Dou ${ }^{c}$

${ }^{\mathrm{a} C o l l e g e}$ of Mechanical and Electronic Engineering, Shandong University of Science and Technology, 266590, Qingdao, Shandong Province, China

${ }^{b}$ School of Chemistry and Chemical Engineering, Shandong Provincial Key Laboratory of Chemical Energy Storage and Novel Cell Technology, College of Materials Science and Engineering, LiaoCheng University, LiaoCheng, 252000, PRC

${ }^{\mathrm{c}}$ Institute for Superconducting and Electronic Materials, Australian Institute for Innovative Materials, University of Wollongong Innovation Campus, North Wollongong New South Wales 2500, Australia

${ }^{\mathrm{d} N e w}$ carbon materials institute, Taiyuan University of Technology, Taiyuan, 030024, PRC

${ }^{\mathrm{e} C o l l e g e}$ of Energy, Key Laboratory of Advanced Carbon Materials and Wearable Energy Technologies of Jiangsu Province, Soochow University, Suzhou, 215006, China E-mail: baizhongchao@tyut.edu.cn

*Corresponding author.

E-mail address: baizhongchao@tyut.edu.cn

E-mail address: zouguifu@suda.edu.cn 


\begin{abstract}
Selenium (Se) is a prospective candidate of electrode material for high-energy batteries. However, the low Se loading, volumetric expansion and polyselenide shuttling between cathode and anode are major factors to limit the further development. To overcome above issues, the hollow carbon structure with interconnected mesopores is used to confine Se composite via a facile annealing treatment route. The Se/HMCS electrode exhibits excellent performance, including a long cycle life $\left(710 \mathrm{~mA} \mathrm{~h} \mathrm{~g}^{-1}\right.$ at the $800^{\text {th }}$ cycle at $0.5 \mathrm{~A} \mathrm{~g}^{-1}$ for LIBs and $291 \mathrm{~mA} \mathrm{~h} \mathrm{~g}^{-1}$ at the $1500^{\text {th }}$ cycle at $0.5 \mathrm{~A} \mathrm{~g}^{-1}$ for SIBs). When coupled with $\mathrm{LiCoO}_{2}$ and $\mathrm{Na}_{3} \mathrm{~V}_{2}\left(\mathrm{PO}_{4}\right)_{3} / \mathrm{C}$ in full cells, this electrode also exhibits superior rate capability (181 $\mathrm{Wh} \mathrm{kg}^{-1}$ total at $20 \mathrm{~W} \mathrm{~kg}^{-1}$ for LIBs and $130 \mathrm{Wh} \mathrm{kg}^{-}$ ${ }_{\text {total }}$ at $52 \mathrm{~W} \mathrm{~kg}^{-1}$ for SIBs). The excellent electrochemical performance is attributed to the unique hollow structure of HMCS and a large amount of Se encapsulated within mesoporous, which not only promote electronic/ionic transport but also provide additional buffer space to adjust the volumetric expansion of Se and polyselenide during long cycling. This facile and novelty strategy could be easily extended to other materials with low electronic conductivity for advanced energy storage systems.
\end{abstract}

Keywords Hollow mesoporous sphere structure, Selenium anode, Lithium-ion batteries, Sodium-ion batteries, Full-cell

\title{
1.Introduction
}


The burning of fossil fuels in the world exacerbates the energy crisis and greenhouse effect, which prompt scientists to develop renewable energy sources such as solar energy, wind, and tides [1]. However, the discontinuity and instability originated from the time-space constraints make the application of these renewable energies are critically limited. Therefore, the development of high-efficient and lowcost energy storage and conversion systems plays a core role to integrate these renewable energies into the smart grid. Rechargeable batteries (LIBs/SIBs), as new and efficient energy storage systems, have been successfully used in many fields such as portable electronics and electric vehicles [2-5]. However, the anode materials (graphite) of LIBs cannot meet the high energy density demand of the future devices due to its inherent low theoretical specific capacity $\left(372 \mathrm{~mA} \mathrm{~h} \mathrm{~g}^{-1}\right)$ [6-8]. Besides, the limitation of lithium source restricts the LIBs large-scale applications. SIBs as the promising replacement of LIBs in grid scale application has aroused great attention in recent years. However, it is even worse for SIBs because the $\mathrm{Na}^{+}$ion is larger than $\mathrm{Li}^{+}$ion $(1.02 \AA$ vs $0.76 \AA$ in radius), which makes $\mathrm{Na}^{+}$ion more difficult to intercalate into graphite interlayer (only $31 \mathrm{~mA} \mathrm{~h} \mathrm{~g}^{-1}$ ) [9-11]. Thus, it is crucial to search for novel anode materials having a high specific capacity and long cycling life to improve the batteries system (LIBs/SIBs).

Recently, Se has attracted considerable attention as electrode materials because of the high volumetric capacity (3253 $\left.\mathrm{mA} \mathrm{h} \mathrm{cm}^{-3}\right)$ and the high electronic conductivity (1 $\times 10^{-3} \mathrm{~S} \mathrm{~m}^{-1}$ ) [12-17]. However, there are yet great challenges exist in Se electrode materials that impede their practical applications. Such challenges mainly involve the 
pulverization aroused by the volume variation of Se and polyselenide, which leads to great loss of the active material and rapid deterioration of cycling stability [18, 19]. In order to highlight advantages of Se electrode materials and make it a practical SIBs/LIBs anode material, one of the common and feasible methods is to confine Se and polyselenides into the carbonaceous matrix, which not only increase electrical conductivity, but also accommodate volume change [11, 20-24]. For example, Sen Xin et al. synthesized Se/micropores carbon composite that maintained a capacity of 300 $\mathrm{mA} \mathrm{h} \mathrm{g} \mathrm{g}^{-1}$ at a current density of $50 \mathrm{~mA} \mathrm{~g}^{-1}$ in LIBs [25]. Zeng and co-workers synthesized a flexible and free-standing porous carbon nanofiber/selenium composite electrode, which delivered a reversible capacity of $500 \mathrm{~mA} \mathrm{~h} \mathrm{~g}^{-1}$ at a current density of $50 \mathrm{~mA} \mathrm{~g}^{-1}$ after 80 cycles in SIBs [26]. Among all the porous carbon materials, mesoporous carbon hollow spheres (MCHS) with porous shells, accessible interior space, high surface area, and large pore volume is considered to be the most suitable carbon matrix for hosting the Se to improve the electrochemical performance $[22,23$, $25,26]$.

Herein, we design and prepare a Se electrode material with hollow mesoporous sphere structure, in which Se is impregnated into the mesoporous carbon sphere (Se/HMCS) with a simple melt-diffusion method. The Se@HCMS electrode delivers superior lithium storage performances in half cell, including an ultralong cycle lifespan (710 $\mathrm{mA} \mathrm{h} \mathrm{g}^{-1}$ at $0.5 \mathrm{~A} \mathrm{~g}^{-1}$ after $800^{\text {th }}$ cycles), and superior rate capability (303 $\mathrm{mA} \mathrm{h} \mathrm{g}^{-}$ ${ }^{1}$ at $\left.3 \mathrm{~A} \mathrm{~g}^{-1}\right)$. More importantly, by coupling with the commercial $\mathrm{LiCoO}_{2}$, it also exhibits excellent performances in full cells. Even at a high power density of $20 \mathrm{~W} \mathrm{~kg}^{-1}$, the 
energy density of full-cell could still be kept at $181 \mathrm{Wh} \mathrm{kg}^{-1}$ total. Meanwhile, the electrochemical properties of the Se/HMCS were examined comprehensively as anode materials for sodium ion half-cell. It delivers a high specific capacity of $291 \mathrm{~mA} \mathrm{~h} \mathrm{~g}^{-1}$ at $0.5 \mathrm{~A} \cdot \mathrm{g}^{-1}$ after $1500^{\text {th }}$ cycles. The rate performance is also excellent $\left(263 \mathrm{~mA} \mathrm{~h} \mathrm{~g}^{-1}\right.$ at $\left.3 \mathrm{~A} \mathrm{~g}^{-1}\right)$. When coupled with homemade $\mathrm{Na}_{3} \mathrm{~V}_{2}\left(\mathrm{PO}_{4}\right)_{3} / \mathrm{C}$ in full cells, it also maintains a reversible capacity of $180 \mathrm{~mA} \mathrm{~h} \mathrm{~g}{ }^{-1}$ after 100 cycles at $0.5 \mathrm{~A} \mathrm{~g} \mathrm{~g}^{-1}$. The superior electrochemical properties are attributed to the unique hollow mesoporous carbon structure and Se encapsulated within mesoporous carbon matrix, improving the conductivity, alleviating the volume change and thus enhancing the cycling stability.

\section{Experimental}

\subsection{Samples Preparation}

\subsubsection{Hollow Mesoporous Carbon Spheres (HMCS)}

Synthesis of $\mathrm{SiO}_{2} @ \mathrm{SiO}_{2} / \mathrm{RF}$ : Firstly, 3.46 mL Tetraethylorthosilicate (TEOS) was added to the solution of $70 \mathrm{~mL}$ ethanol, $10 \mathrm{~mL} \mathrm{H}_{2} \mathrm{O}$ and $3 \mathrm{~mL}$ ammonia $(25 \mathrm{wt} \%)$ at room temperature with $15 \mathrm{~min}$ stirring; Secondly, $0.4 \mathrm{~g}$ of resorcinol and $0.56 \mathrm{~mL}$ of formaldehyde (37 wt $\%$ ) were added to the prepared solution under stirring for $24 \mathrm{~h}$ at room temperature. The final solution was carefully collected and washed with distilled water and ethanol three times, and dried in a vacuum oven at $60{ }^{\circ} \mathrm{C}$ for $12 \mathrm{~h}$.

Synthesis of $\mathrm{SiO}_{2} @ \mathrm{SiO}_{2} / \mathrm{C}$ : The as-prepared samples were annealed at $700{ }^{\circ} \mathrm{C}$ $\left(2{ }^{\circ} \mathrm{C} \mathrm{min}^{-1}\right)$ for $5 \mathrm{~h}$ in $\mathrm{N}_{2}$ gas to carbonize the polymer into carbon.

Synthesis of HMCS: The black product after annealing was dispersed into $1 \mathrm{M}$ $\mathrm{NaOH}$ to remove the silica template, forming hollow mesoporous carbon spheres. 


\subsubsection{Selenium@Hollow Mesoporous Carbon Spheres (Se@HMCS) Composite}

Se powder $(99.99 \%)$ and HMCS with a weight ratio of 110:45 were mixed and heated at $160{ }^{\circ} \mathrm{C}$ for $12 \mathrm{~h}$ followed by $350{ }^{\circ} \mathrm{C}$ for $3 \mathrm{~h}$ in $\mathrm{N}_{2}$ atmosphere to obtain Se@HMCS.

\subsection{Samples Characterization}

General microstructure and morphology of the samples were performed by a scanning electron microscopy (SEM) (JEOL JSM-7100F) and a transmission electron microscope (TEM) (JEOL JEM 1011 and JEOL2100, Japan). X-ray diffraction (Bruker D8 Adv, Germany) was employed to identify the composition and crystal structure of the synthesized samples. XPS measurements were recorded on a Thermo Scientific KAlpha using an $\mathrm{Al} \mathrm{K} \alpha \mathrm{X}$-ray source. Thermo-gravimetric analysis (TGA) was used to examine the Se content in the composite (in $\mathrm{N}_{2}$ atmosphere). Raman spectra were acquired on a NEXUS 670 Raman spectrometer, using excitation at $632 \mathrm{~nm}$ at room temperature. $\mathrm{N}_{2}$ adsorption-desorption isotherms of the prepared composites were measured using an ASAP-2010 surface area analyzer.

\subsection{Electrochemical Measurements}

The electrode fabricated by Se@HMCS composites, acetylene black and carboxymethyl cellulose (CMC) with a weight ratio of $8: 1: 1$, and using DI water as a solvent. The forming slurries were pasted onto copper foil and then dried under vacuum at $60{ }^{\circ} \mathrm{C}$ for $12 \mathrm{~h}$. The loading mass of active materials on the individual electrode was about $1.0 \mathrm{mg} \mathrm{cm}^{-2}$. Afterwards, CR2032-type coin cell was assembled in an argon-filled glove box. The Li-ion battery electrolyte was $1 \mathrm{M} \mathrm{LiPF}_{6}$ in ethylene carbonate (EC), 
dimethyl carbonate (DMC) and ethyl methyl carbonate (EMC) (v/v/v $1: 1: 1)$. The electrolyte was $1 \mathrm{M} \mathrm{NaClO}_{4}$ dissolved in a mixture of $\mathrm{EC}$ and propylene carbonate (PC) $(1: 1$, by volume ratio) with $5 \mathrm{wt} \%$ fluoroethylene carbonate (FEC) solution as the Naion battery electrolyte. The cyclic voltammetry (CV) curves were studied by a CHI760E electrochemistry workstation from $3.0 \mathrm{~V}$ to $0.01 \mathrm{~V}$ (vs. $\mathrm{Li} / \mathrm{Li}^{+}$and vs. $\mathrm{Na} / \mathrm{Na}^{+}$) at a scan rate of $0.1 \mathrm{mV} \mathrm{s}^{-1}$. Galvanostatic measurements were conducted on LAND CT2001A battery test system between $3.0 \mathrm{~V}$ to $0.01 \mathrm{~V}$.

For the cathode material as Li-ion half cells, the cathode was used of commercial $\mathrm{LiCoO}_{2}$, acetylene black, and polyvinylidene fluoride (PVDF) in a weight ratio of 8:1:1 on an aluminum foil. Galvanostatic measurements were conducted on LAND CT2001A battery test system between 4.5 V to 3.2 V. For Li-ion full cells, the anode (Se@HMCS) need not pre-lithium. The capacity ratio of anode (Se@HMCS)/cathode $\left(\mathrm{LiCoO}_{2}\right)$ was controlled around 1:1.3. Galvanostatic measurements were conducted on LAND CT2001A battery test system between $4.0 \mathrm{~V}$ to $0.8 \mathrm{~V}$.

For the cathode material as Na-ion half cells, the cathode was used of homemade $\mathrm{Na}_{3} \mathrm{~V}_{2}\left(\mathrm{PO}_{4}\right)_{3} / \mathrm{C}$, acetylene black, and polyvinylidene fluoride (PVDF) in a weight ratio of 8:1:1 on an aluminum foil. Galvanostatic measurements were conducted on LAND CT2001A battery test system between $3.8 \mathrm{~V}$ to $2.5 \mathrm{~V}$. For Na-ion full cells, the anode (Se@HMCS) also need not pre-sodium. The capacity ratio of anode (Se@HMCS)/cathode $\left(\mathrm{Na}_{3} \mathrm{~V}_{2}\left(\mathrm{PO}_{4}\right)_{3} / \mathrm{C}\right)$ was controlled around 1:1.3. Galvanostatic measurements were conducted on LAND CT2001A battery test system between $4.2 \mathrm{~V}$ to $1.2 \mathrm{~V}$. The capacity of Se/HCMS calculated based on the mass of Se/HCMS 
composite.

\section{Results and discussion}

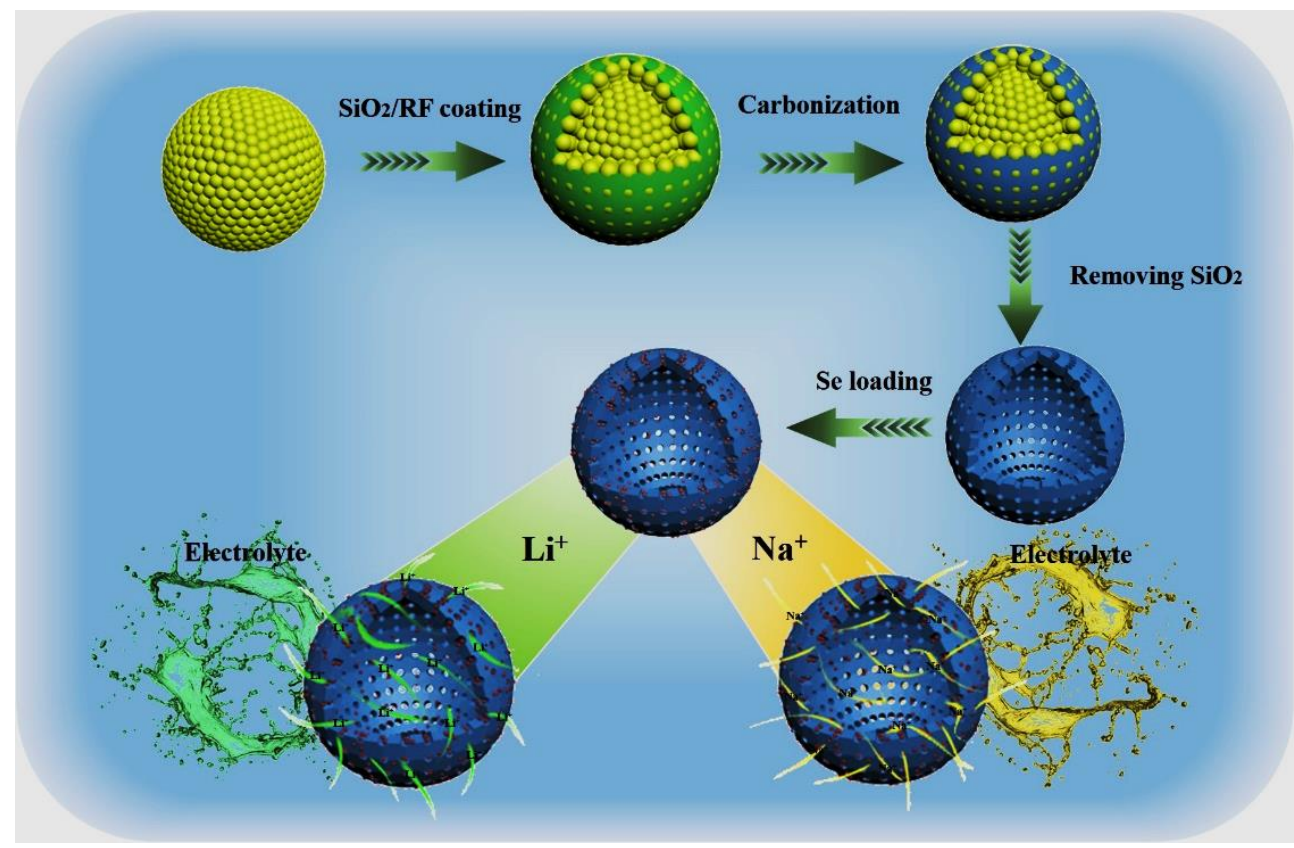

Scheme 1. Illustrates the fabrication process of Se@HMCS composites.

The strategy for synthesizing the Se@HMCS is shown in Scheme 1. Firstly, tetraethylorthosilicate (TEOS) and resorcinol formaldehyde (RF) oligomers were cocondensed on $\mathrm{SiO}_{2}$ core particles to form the $\mathrm{SiO}_{2} @ \mathrm{SiO}_{2} / \mathrm{RF}$ with a uniform average size of $\sim 300 \mathrm{~nm}$ core-shell nanospheres (Figure S1) (step I, Scheme 1). Secondly, the $\mathrm{SiO}_{2} @ \mathrm{SiO}_{2} / \mathrm{RF}$ was thermally treated at $700{ }^{\circ} \mathrm{C}$ for $5 \mathrm{~h}$ in $\mathrm{N}_{2}$ gas to carbonize the polymer into carbon (Figure S2) (step II, Scheme 1), followed by treatment by $\mathrm{NaOH}$ to remove $\mathrm{SiO}_{2}$ template, achieving hollow mesoporous carbon spheres (HMCS) (Figure S3) (step III, Scheme 1). Afterwards, Se@HMCS composite was obtained through a facile melt diffusion procedure (step IV, Scheme 1). 

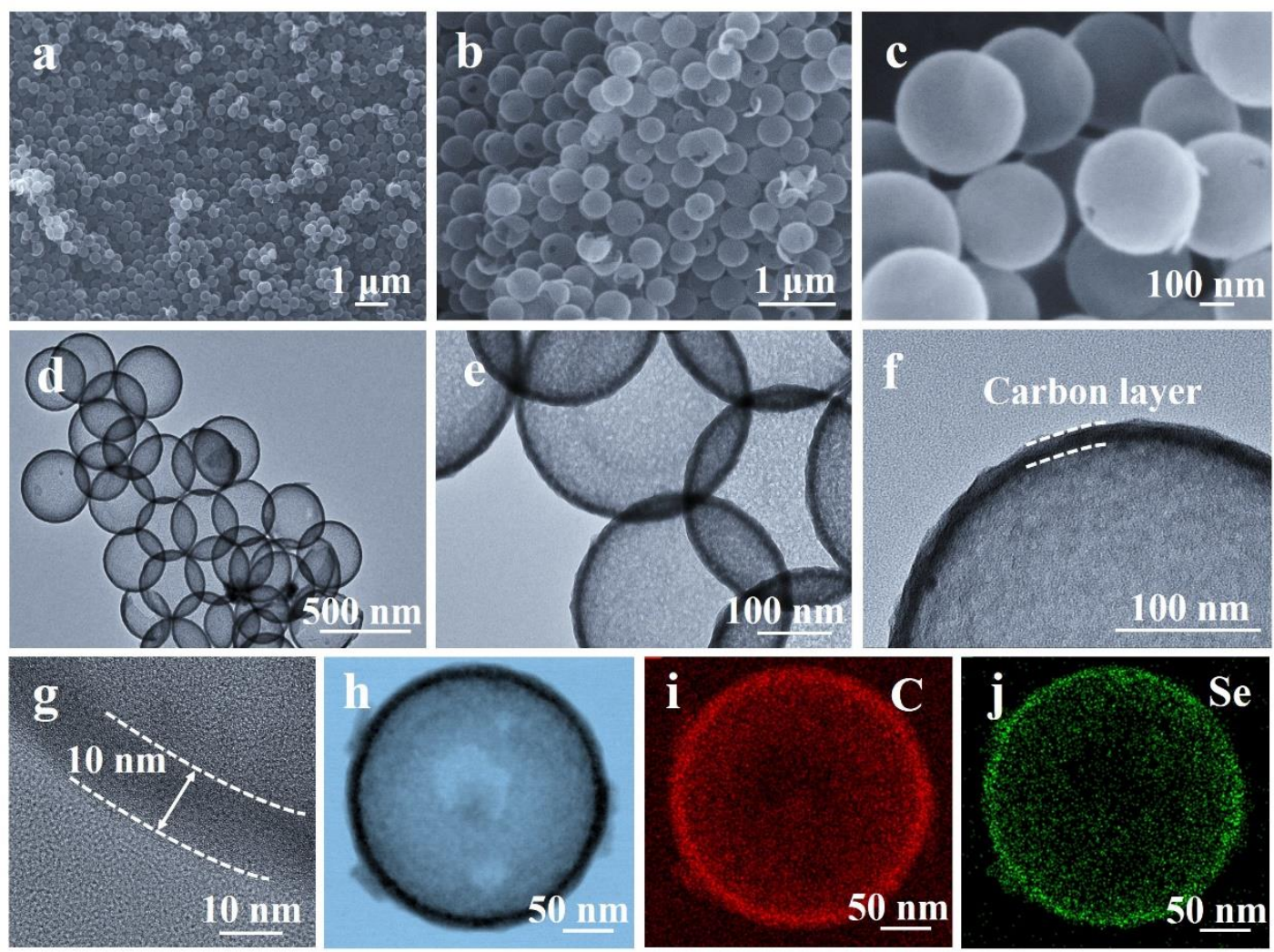

Figure 1. (a) Low and (b, c) High resolution SEM images of the Se@HMCS composites. (d) Low and (e, f) High resolution TEM images of the Se@HMCS composites. (g) High resolution TEM image of the Se@HMCS composites. (h-j) Elemental mapping of the Se@HMCS composites.

Figure 1 reveals the microstructures and morphologies of the Se@HMCS composites by SEM and TEM. The SEM images of Se@HMCS composites exhibit similar morphological of HMCS with a diameter of $\sim 300 \mathrm{~nm}$ and shell thickness of $\sim 10 \mathrm{~nm}$ (Figure 1a-c and f). The hollow structure is disclosed by some broken spheres (Figure 1b). This result is supported by the TEM images. As shown in Figure 1d and e, the obvious contrast indicates the hollow and porous structure nature of Se@HMCS. The HRTEM lattice diagram (Figure 1g) shows that there are no distinct lattice fringes for Se@HCMS composites, indicating the amorphous Se and carbon in the Se@HCMS 
composites. The elemental mapping of Se@HCMS composites (Figure 1h-j) demonstrates the homogenous distribution of Se in the carbon material without any Se bulk. All the above results indicate that the Se has been impregnated into the mesoporous of HCMS.
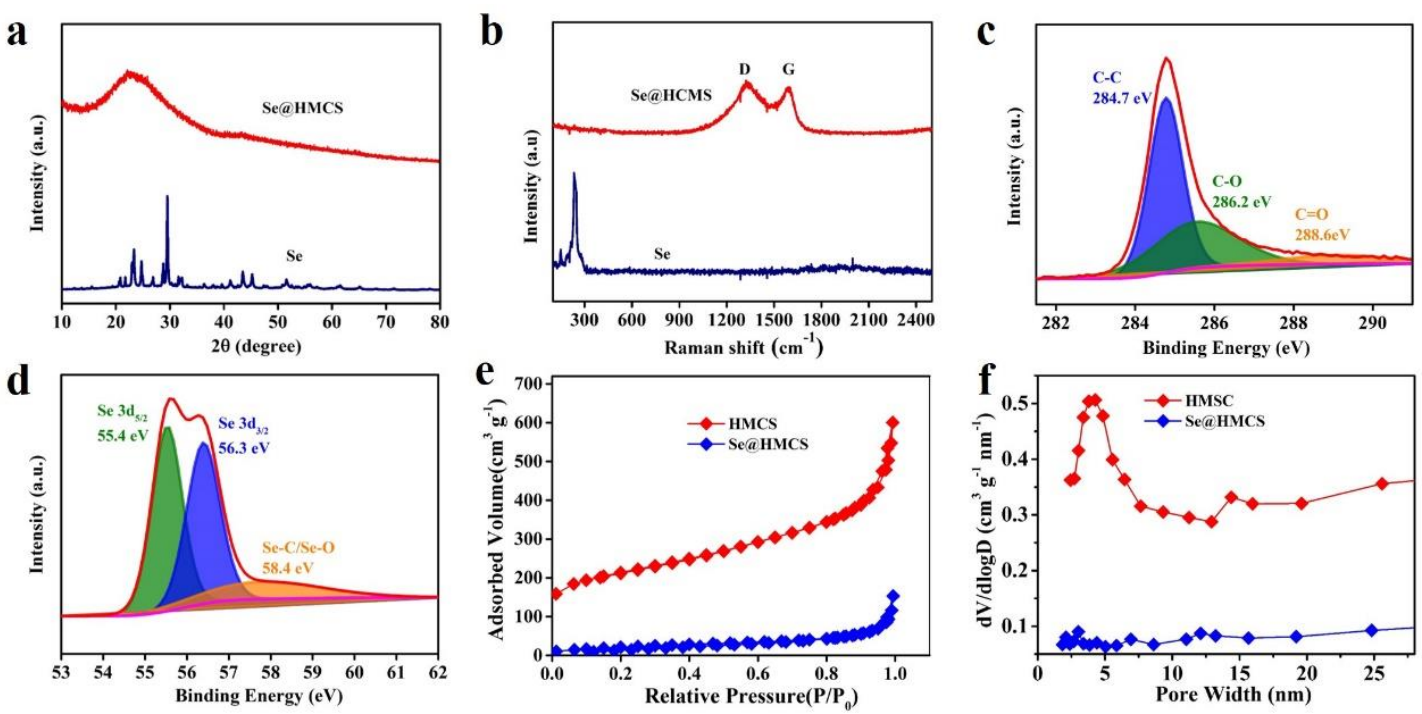

Figure 2. (a) XRD patterns of the Se and Se@HCMS. (b) Raman spectrum of the Se and Se@HCMS. XPS spectra of Se@HCMS: (c) C 1s. (d) Se 3d. (e) Nitrogen adsorption-desorption isotherms of HMCS and Se@HMCS composites. (f) corresponding pore size distributions curves of HMCS and Se@HMCS composites.

The composition of the samples was analyzed by the X-ray diffraction (XRD). Figure 2a displays the highly crystalline of pristine Se. After impregnated into the carbon materials, all the characteristic peaks of Se disappear. The disappearance of Se peaks in XRD patterns indicates there is no bulk crystalline Se in the composite after heat treatment, which may lead to better electrochemical performance [27-29]. The results of the XRD analysis are also consistent with Raman spectra. As shown in Figure $\mathbf{2 b}$, the pristine Se shows one peak at $142 \mathrm{~cm}^{-1}$ (ring structure of Se) and one peak at 
$236 \mathrm{~cm}^{-1}$ (chain structure of Se) [30]. However, there is no obvious the peaks of Se in the Se@HMCS composites, demonstrating all of the pristine Se powder is diffused into the pores of mesoporous carbon spheres after the heating process [31]. The two distinct peaks at 1345 and $1570 \mathrm{~cm}^{-1}$ are ascribed to the disordered carbon (D band) and graphitized carbon (G band), respectively [32]. The intensity ratio of $I \mathrm{D} / I \mathrm{G}$ (about 1.03 ) reflects low graphitization degree of the carbon [33]. The Se content in the Se@HMCS composites was elevated by the thermogravimetric analysis (TGA) in $\mathrm{N}_{2}$ flow from room temperature to $800{ }^{\circ} \mathrm{C}$ (Figure S4). The Se content in the Se@HMCS is $55.7 \mathrm{wt} \%$ determined by the TGA curve.

The chemical bonding state of the Se@HMCS composites was further examined by X-ray photoelectron spectroscopy (XPS) measurements. The survey spectrum of Se@HMCS composites shows the presence of the elements C, Se and O (Figure S5). The C1s spectrum in Figure 2c is divided into C-C $(284.7 \mathrm{eV}), \mathrm{C}-\mathrm{O}(286.2 \mathrm{eV})$ and $\mathrm{C}=\mathrm{O}(288.6 \mathrm{eV})$ peaks [34]. The Se spectrum is fitted into three peaks at $55.4 \mathrm{eV}, 56.3$ $\mathrm{eV}$ and $58.4 \mathrm{eV}$, corresponding to $\mathrm{Se} 3 \mathrm{~d}_{5 / 2}, \mathrm{Se} 3 \mathrm{~d}_{3 / 2}$ and $\mathrm{Se}-\mathrm{C} / \mathrm{Se}-\mathrm{O}$, respectively (Figure 2d) $[35,36]$. Nitrogen adsorption-desorption tests were used to analyses the specific surface area and pore size distribution of the HMCS and Se@HMCS composites. Figure 2e shows the Brunauer-Emmett-Teller (BET) surface area decreases from 690 of the HMCS to $81 \mathrm{~m}^{2} \mathrm{~g}^{-1}$ of the Se@HMCS, implying a significant reduction in poresize in the mesoporous region (about $3.9 \mathrm{~nm}$ ) due to the Se loading in HMCS (Figure 2f), which is consistent with the XRD and Raman results. 

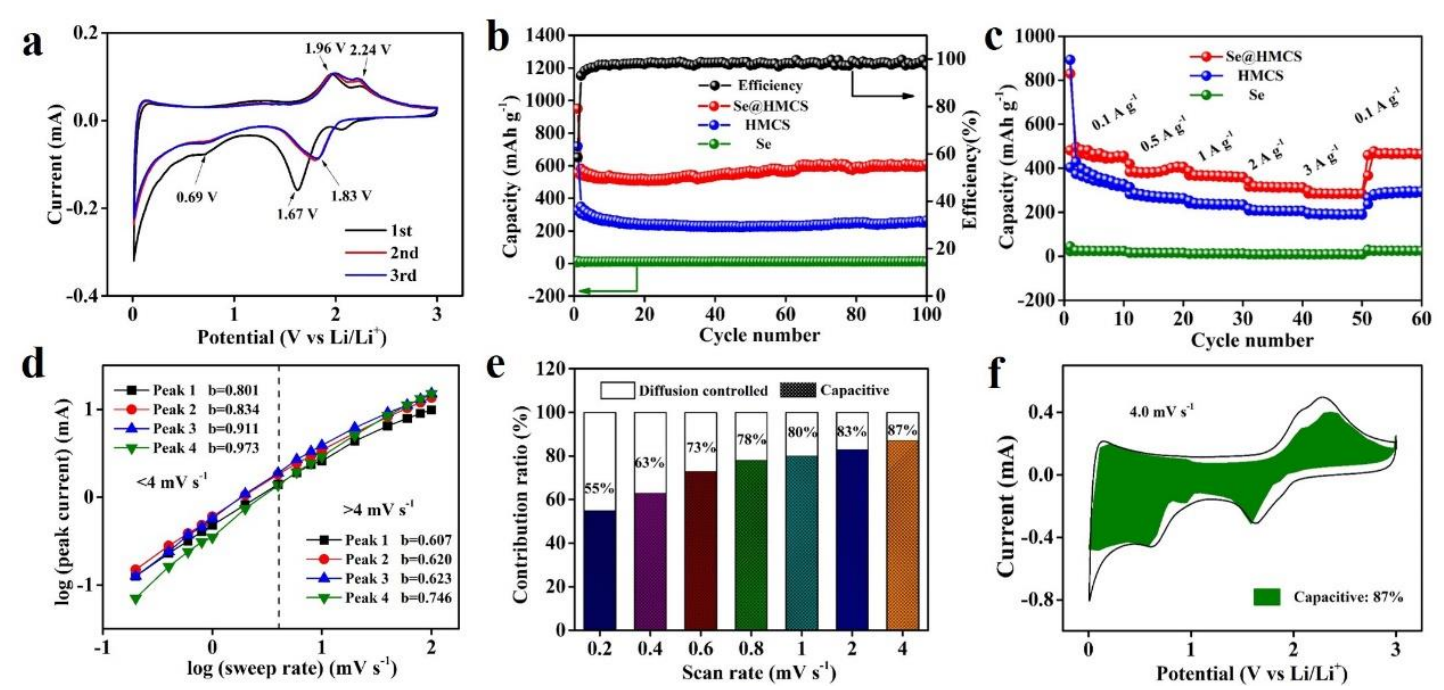

Figure 3. The Se@HMCS composites as anode materials for LIBs: (a) CV curves at a scan rate of $0.1 \mathrm{mV} \mathrm{s}^{-1}$ for the first three cycles. (b) Cycle stability of $\mathrm{Se} @ \mathrm{HCMS}$ composites, HMCS and Se at $0.05 \mathrm{~A} \mathrm{~g}^{-1}$. (c) Rate performance of Se@HCMS composites, HMCS and Se. (d) $b$ value obtained by plots of $\log (i)$ versus $\log (v)$, calculated from reduction and oxidation states of CV curves. (e) Diagram of the capacitive contribution to the total capacity at different scan rates. (f) $\mathrm{CV}$ profile showing the capacitive contribution (the filled part) of the Se@HMCS electrode at a scan rate of $4.0 \mathrm{mV} \mathrm{s}^{-1}$.

The electrochemical performances of the Se@HMCS electrode were evaluated in the voltage window of $0.01-3.0 \mathrm{~V}\left(\mathrm{vs} . \mathrm{Li}^{+} / \mathrm{Li}\right.$ ). Figure 3a shows the typical cyclic voltammetry (CV) curves of the Se@HMCS electrode in the first three cycles at 0.1 $\mathrm{mV} \mathrm{s}^{-1}$. During the initial cathodic process, a board peak of $1.67 \mathrm{~V}$ and a weak peak centered at $0.69 \mathrm{~V}$ are attributed to the reduction of elemental $\mathrm{Se}$ to $\mathrm{Li}_{2} \mathrm{Se}_{\mathrm{n}}(\mathrm{n} \geq 4)$, as well as the formation of solid electrolyte interphase (SEI) layer [30, 37]. Two oxidation peaks at $1.96 \mathrm{~V}$ and $2.24 \mathrm{~V}$ are observed in the anodic process, which is attributed to the delithiation of $\mathrm{Li}_{2} \mathrm{Se}$. After the first cycle, the cathodic peak at $1.67 \mathrm{~V}$ shifts to a 
higher voltage of $1.83 \mathrm{~V}$, while the peak at $0.69 \mathrm{~V}$ remains at its original position with decreased intensity due to the irreversible formation of SEI layer. The CV peaks almost overlap each other in the subsequent cycles, suggesting the good cycling stability of the Se@HMCS electrode in the lithium half-cell.

Figure S6 displays the $1^{\text {st }}, 50^{\text {th }}$ and $100^{\text {th }}$ charge/discharge profiles of the Se@HMCS electrode at a current density of $0.05 \mathrm{~A} \mathrm{~g}^{-1}$. The discharge profile presents two slope voltage plateaus, demonstrating the two step reactions during the lithiation process, which is agreement with $\mathrm{CV}$ examination. Interestingly, the charge and discharge profiles of $50^{\text {th }}$ and $100^{\text {th }}$ cycle basically overlap with each other, and the Se@HMCS electrode can still maintain an excellent reversible capacity of 603.4 mA h $\mathrm{g}^{-1}$ after 100 cycles (Figure 3b), suggesting its outstanding stability and reversibility in the half cell of LIBs.

The rate capability of Se@HMCS was assessed at various current densities. As shown in Figure 3c, the synthesized sample delivered specific capacities of 486, 415, 389,345 and $303 \mathrm{~mA} \mathrm{~h} \mathrm{~g}^{-1}$ at rates of $0.1,0.5,1,2$ and $3 \mathrm{Ag}^{-1}$, respectively. Furthermore, its capacity recovers back to the initial value $\left(485 \mathrm{~mA} \mathrm{~h} \mathrm{~g}^{-1}\right)$ when the current density returns to $0.1 \mathrm{~A} \mathrm{~g}^{-1}$. In contrast, the HCMS and Se materials deliver much lower reversible capacity and rate performance than the Se@HMCS electrode due to the low electronic conductivity (Figure $\mathbf{3 b}, \mathbf{c}$ ). Figure $\mathbf{S 7 a}$ reveals the long cycling performance of Se@HMCS electrode at $0.5 \mathrm{~A} \mathrm{~g}^{-1}$ for $800^{\text {th }}$ cycles. It delivers a reversible capacity of $710 \mathrm{~mA} \mathrm{~h} \mathrm{~g}^{-1}$ after $800^{\text {th }}$ cycles which is higher than the initial cycles is due to the electrode activation (Figure S7b) [20]. In the first several cycles, 
the irreversible capacity results from some side reactions and the formation of SEI [30, 37]. In addition, the activation of the electrode materials may be another possible reason to the increasing trend. The superior electrochemical performance of Se@HMCS come from its unique structure, which can not only enhance the electron conductivity, but also accommodate the volume expansion [36, 38]. More importantly, the Se@HMCS composites electrode kept its structure after cycling (Figure S8). In addition, the long cycling and rate performance of the Se@HMCS electrode are superior to other Se-based electrodes for LIBs (Figure S9a).

In order to further understand the excellent cycle stability and high rate capacity of the Se@HMCS electrode as anode for LIBs, the CV curves of the Se@HMCS electrode at different scan rates, from 0.2 to $100 \mathrm{mV} \mathrm{s}^{-1}$, were collected to analyze the kinetic properties (Figure S9b). The similar shape of CV curves in the range of 0.2-100 $\mathrm{mV} \mathrm{s}^{-1}$ indicates the characteristic of pseudocapacitive behavior [39]. Figure 3d shows the $b$ values obtained by the slope of the plot of $\log (i)$ versus $\log (v)$ according to the following equation [39-41]:

$i=a v^{b}$

( $i$ : current density; $v$ : sweep rate; $a, b$ : constants). Previous reports have indicated that the $b$ value of 1.0 reflects a surface capacitive contribution (capacitor-type) $\left(k_{1} v\right)$, while the $b$ value of 0.5 is diffusion-controlled contribution (battery-type) $\left(k_{2} v^{1 / 2}\right)$. For Se@HMCS electrode as LIBs from 0.2 to $4 \mathrm{mV} \mathrm{s}^{-1}$, the $b$ values of the anodic peak 1 and 2 are 0.801 and 0.834 . The $b$ values of the cathodic peak 3 and 4 are 0.911 and 0.973, respectively, illustrating the high contribution of capacitive behavior. Meanwhile, 
the cathodic peak 4 shifts a little $(<0.18 \mathrm{~V})$ (Figure S9c), indicating small polarization and fast kinetics [42]. Larger than the scan rate of $4 \mathrm{mV} \mathrm{s}^{-1}$, the $b$ values of the anodic peak 1 and 2 decreases to 0.607 and 0.620 , and the $b$ values of the cathodic peak 3 and 4 are 0.623 and 0.746 , respectively. The results may be due to the increasing resistance and diffusion constraints at a high rate.

The relationship between the normalized capacity and sweep rate distinguishes the charge storage mechanism, could be divided into two regions (Figure S9d) [43]. When the sweep rate is less than $4 \mathrm{mV} \mathrm{s}^{-1}$, the normalized capacitance is approximately linear with $v^{-1 / 2}$, which demonstrates the independence of the capacitance contribution relative to sweep rate. Therefore, the process is attributed to surface capacitive contribution. Interestingly, with increasing of sweep rate above $4 \mathrm{mV} \mathrm{s}^{-1}$, the normalized capacity decreases rapidly, indicating the contribution of diffusion-controlled. The equation:

$i(V)=k_{1} v+k_{2} v^{1 / 2}$

could clearly and quantitatively distinguish the contributions capacitor-type and battery-type at a fixed voltage. As shown in Figure 3e, the capacitive contribution rises with increasing sweep rate. When the sweep rate up to $4 \mathrm{mV} \mathrm{s}^{-1}$, the rate of capacitive contribution can reach $87 \%$ of the total capacity (Figure 3f). The long cycling stability and high rate capacity are attributed to the pseudocapacitive behavior. 

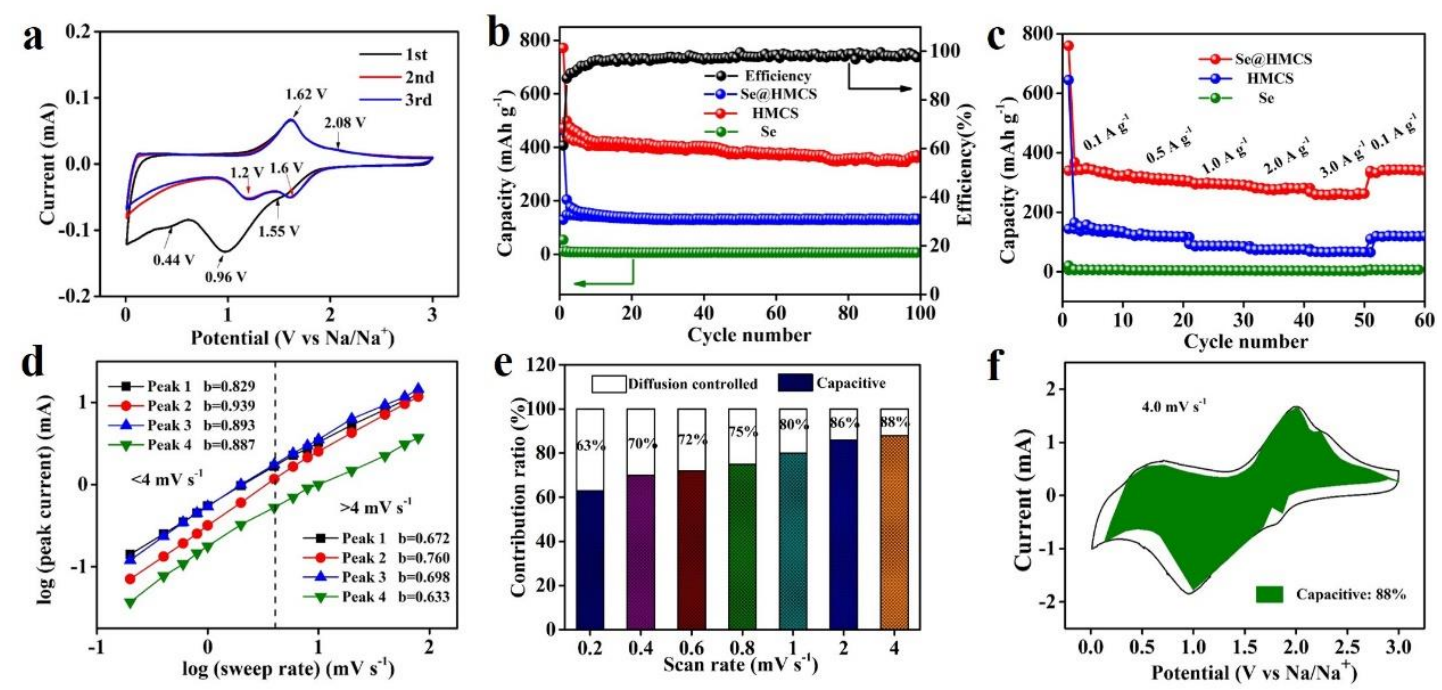

Figure 4. The Se@HMCS composites as anode materials for SIBs: (a) CV curves at a scan rate of $0.1 \mathrm{mV} \mathrm{s}^{-1}$ for the first three cycles. (b) Cycle stability of HCMS and Se@HMCS composites at $0.05 \mathrm{~A} \mathrm{~g}^{-1}$. (c) Rate performance of Se@HCMS composites, HMCS and Se. (d) b value obtained by plots of $\log (i)$ versus $\log (v)$, calculated from reduction and oxidation states of CV curves. (e) Diagram of the capacitive contribution to the total capacity at different scan rates. (f) $\mathrm{CV}$ profile showing the capacitive contribution (the filled part) of the Se@HMCS electrode at a scan rate of $4.0 \mathrm{mV} \mathrm{s}^{-1}$.

The sodium half-cell performances of the Se@HMCS electrode are comprehensively evaluated in the voltage window of $0.01-3.0 \mathrm{~V}\left(\mathrm{vs} . \mathrm{Na}^{+} / \mathrm{Na}\right)$. The $\mathrm{CV}$ curves of the initial 3 cycles for the Se@HMCS electrode is shown in Figure 4a. In the first cathodic process, the two peaks at $1.55 \mathrm{~V}$ and $0.96 \mathrm{~V}$ are attributed to the reduction of Se to generate $\mathrm{Na}_{2} \mathrm{Se}[39]$. Another peak at 0.44 disappears after the first cycle, indicating the formation of solid electrolyte interphase (SEI) film [44, 33]. The two cathodic peaks shift towards a higher voltage $(1.2 \mathrm{~V}$ and $1.6 \mathrm{~V})$ from the second cycle due to the electrode activity. In the anodic process, the two peaks at $1.62 \mathrm{~V}$ and $2.08 \mathrm{~V}$ correspond to the conversion reaction of $\mathrm{Na}_{2} \mathrm{Se}$, reversibly producing of elemental $\mathrm{Se}$ 
$[45,46]$. After the first cycle, CV curves exhibit excellent overlapping, suggesting good cycling stability of electrode reactions during the discharge/charge processes [33]. The CV results are well consistent with the discharge/charge profiles at a current density of $0.05 \mathrm{~A} \mathrm{~g}^{-1}$ (Figure S10).

The cycling performance of Se@HMCS electrode as anode for half-cell of SIBs was first examined at a current density of $0.05 \mathrm{~A} \mathrm{~g}^{-1}$ (Figure $4 \mathbf{b}$ ). It remained a capacity of about 400 mA h g${ }^{-1}$ after 100 cycles. The rate performance of Se@HMCS electrode was also studied, and shown in Figure 4c. It delivered specific capacities of $370 \mathrm{~mA} \mathrm{~h}$ $\mathrm{g}^{-1}$ at $0.1 \mathrm{~A} \mathrm{~g}^{-1}, 342 \mathrm{~mA} \mathrm{~h} \mathrm{~g}^{-1}$ at $0.5 \mathrm{~A} \mathrm{~g}^{-1}, 315 \mathrm{~mA} \mathrm{~h} \mathrm{~g}^{-1}$ at $1.0 \mathrm{~A} \mathrm{~g}^{-1}, 289 \mathrm{~mA} \mathrm{~h} \mathrm{~g}^{-1}$ at 2.0 $\mathrm{A} \mathrm{g}^{-1}$, and $280 \mathrm{~mA} \mathrm{~h} \mathrm{~g}^{-1}$ at $3.0 \mathrm{~A} \mathrm{~g}^{-1}$. When current density backs to $0.1 \mathrm{~A} \mathrm{~g}^{-1}$, a capacity of $370 \mathrm{~mA} \mathrm{~h} \mathrm{~g}^{-1}$ was returned. High reversible capacity of $291 \mathrm{~mA} \mathrm{~h} \mathrm{~g}^{-1}$ was achieved after 1500 cycles at a high rate of $0.5 \mathrm{~A} \mathrm{~g}^{-1}$ (Figure S11). In comparison, Se and HCMS electrodes displayed lower specific capacity and inferior rate capabilities than Se@HMCS electrode (Figure 4b, c). Furthermore, the Se@HMCS electrode delivered longer cycling stability and higher rate performance in comparison to others Se-based electrode for SIBs (Figure S13a). The high specific capacity, long cycling stability and good rate performance make Se@HMCS composites a promising anode for advanced SIBs. Those results demonstrated that the HMCS played an essential role in improving the electrochemical of Se due to the enhanced electronic conductivity, buffering space to accommodate the volumetric expansion of Se and restriction of polyselenide during long cycling. Importantly, the micromorphology of the Se@HMCS composites electrode could keep its original structure after cycling (Figure S12). 
For better understanding the outstanding electrochemical performance of Se@HCMS electrode as anode for SIBs, the CV curves at different scan rates $(0.2-100$ $\mathrm{mV} \mathrm{s}^{-1}$ ) were detected to analyze the kinetic properties (Figure S13b) [47]. Through explaining for LIBs, we know that the $b$ value of 1.0 reflects a capacitor-type, while the $b$ value of 0.5 is a battery-type. For Se@HMCS electrode as SIBs from 0.2 to $4 \mathrm{mV} \mathrm{s}^{-}$ , the $b$ values of the anodic peak 1 and 2 are 0.829 and 0.939 , and the $b$ values of the cathodic peak 3 and 4 are 0.893 and 0.887 (Figure 4d), respectively, indicating the high contribution of capacitor-type [48, 49]. At the same time, slightly moving the cathode peak $4(<0.18 \mathrm{~V})$ indicates that the polarization is smaller, and the kinetic is faster (Figure S13c). Above the scan rate of $4 \mathrm{mV} \mathrm{s}^{-1}$, the $b$ values of the anodic peak 1 and 2 decreases to 0.672 and 0.760 , and the $b$ values of the cathodic peak 3 and 4 are 0.698 and 0.633 , respectively, which is due to the increased resistance at a high rate.

As shown in Figure S13d, it should be noted that there are two different regions in the diagram. For the sweep rates $<4.0 \mathrm{mV} \mathrm{s}^{-1}$, the normalized capacity is largely independent of the sweep rates, indicating the high contribution of surface capacity. For the sweep rates $>4.0 \mathrm{mV} \mathrm{s}^{-1}$, the normalized capacity is dependent on the sweep rates, indicating the high contribution of diffusion capacity. The capacitive contribution (the filled part) gradually improves with increasing of sweep rates (Figure 4e), and reaches $88 \%$ up to $4 \mathrm{mV} \mathrm{s}^{-1}$ (Figure $4 \mathbf{f}$ ). The result indicates that the high rate capability is attributed to the suppressed diffusion. 

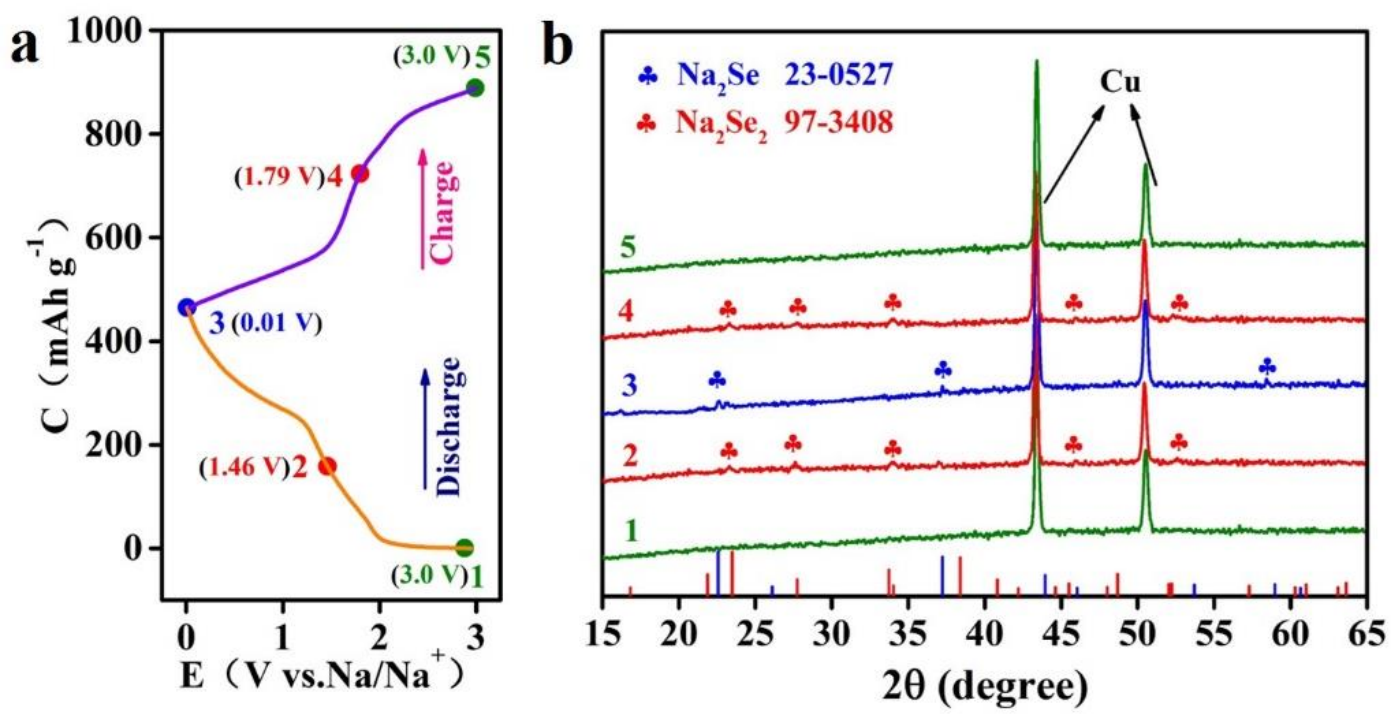

Figure 5. (a) Discharge and charge profiles of the fifth cycle for SIBs. (b) XRD patterns of the Se@HCMS electrode at each stage labeled in (a).

The gradual sodium insertion/extraction of Se during the fifth cycle was examined by ex situ XRD (Figure 5). After discharge to $1.46 \mathrm{~V}$ in Figure 5a, the Se is converted to $\mathrm{Na}_{2} \mathrm{Se}_{2}$, as the characteristic diffraction peaks of $\mathrm{Na}_{2} \mathrm{Se}_{2}$ appear at $23.4^{\circ}, 27.7^{\circ}, 34.0^{\circ}$, $52.0^{\circ}$, and $57.1^{\circ}$ (Figure 5b). The peaks of $\mathrm{Na}_{2} \mathrm{Se}_{2}$ completely disappear when discharge to $0.1 \mathrm{~V}$, and all the peaks correspond to $\mathrm{Na}_{2} \mathrm{Se}\left(22.5^{\circ}, 37.2^{\circ}\right.$, and $\left.58.9^{\circ}\right)$. These results demonstrate that Se first undergoes sodiation into $\mathrm{Na}_{2} \mathrm{Se}_{2}$, and then to $\mathrm{Na}_{2} \mathrm{Se}$. In the charging process, the XRD patterns show the gradual desodiation of $\mathrm{Na}_{2} \mathrm{Se}$, which first forms $\mathrm{Na}_{2} \mathrm{Se}_{2}$ and then returns to the original Se. Therefore, the presence of two typical plateaus at $1.6 / 2.08 \mathrm{~V}$ and $1.2 / 1.62 \mathrm{~V}$ correspond to the reaction of $\mathrm{Se} \leftrightarrow \mathrm{Na}_{2} \mathrm{Se}_{2}$ and $\mathrm{Na}_{2} \mathrm{Se}_{2} \leftrightarrow \mathrm{Na}_{2} \mathrm{Se}$, respectively. This is total agreement with our CV results. 
a
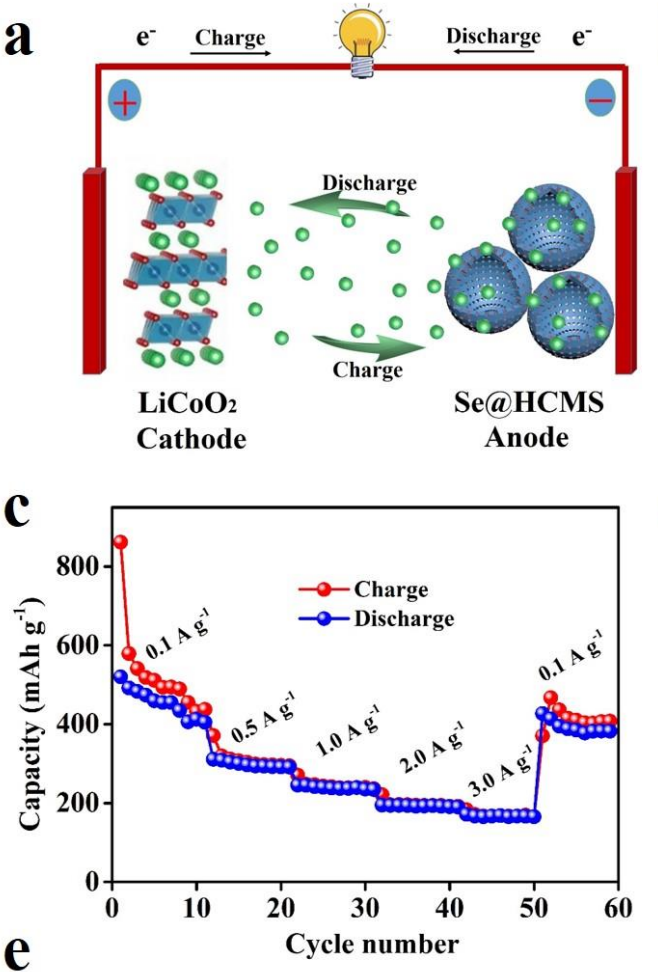

$\mathbf{e}$

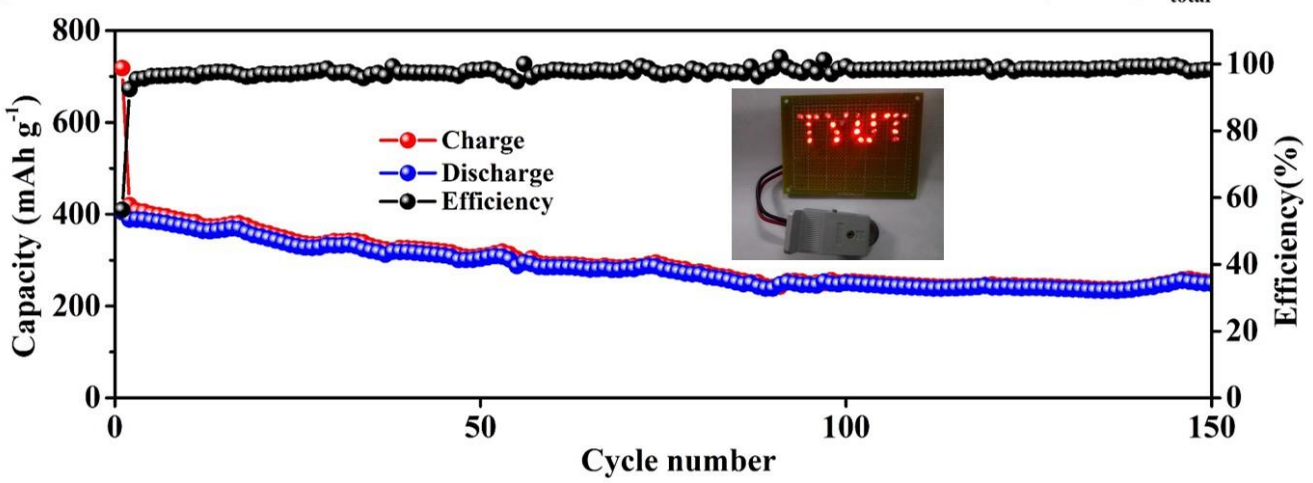

Figure 6. Se@HMCS//LiCoO 2 Li-ion full cell: (a) Schematic illustration of the full cell with $\mathrm{Se} @ \mathrm{HMCS}$ anode and $\mathrm{LiCoO}_{2}$ cathode. (b) Charge/discharge curves at different rates (the capacity is calculated by the mass of anode). (c) Rate performance at different rates (the capacity is calculated by the mass of anode). (d) Ragone plot of this full battery about the power and energy density (they are evaluated by the mass of total). (e) Cycling performance at $0.5 \mathrm{~A} \mathrm{~g}^{-1}$ anode (the capacity is calculated by the mass of anode and the digital inset "TYUT" image of the light-emitting diode lit by the LIBs full battery). 
The excellent electrochemical properties of Se@HMCS electrode urge us to study the performance of lithium ion full-cell. In the full-cell, we selected the Se@HMCS material as anode and the commercial $\mathrm{LiCoO}_{2}$ as the cathode (Figure S14 and Figure 6a). Figure S15 showed the excellent cycling and high rate performance of the commercial $\mathrm{LiCoO}_{2}$, which delivered a high capacity of $180 \mathrm{~mA} \mathrm{~h} \mathrm{~g}^{-1}$ at the current density of $0.1 \mathrm{~A} \mathrm{~g} \mathrm{~g}^{-1}$. Figure $6 \mathbf{b}$ displayed charge/discharge curves at different rates of $\mathrm{Se} @ \mathrm{HMCS} / / \mathrm{LiCoO}_{2}$ full-cell in the voltage range of $0.8-4.0 \mathrm{~V}$. With the increasing of rates, the voltage platform and reversible capacity decrease slightly, which prove to be a better rate performance for the Li-ion full-cell. The rate performance of the Li-ion full-cell was tested and shown in Figure 6c. Se@HMCS//LiCoO $\mathrm{Hull}_{2}$ full exhibited specific capacities of $470,308,245,194$, and $170 \mathrm{~mA} \mathrm{~h} \mathrm{~g}^{-1}$ at $0.1,0.5,1,2$, and $3 \mathrm{~A} \mathrm{~g}^{-}$ ${ }^{1}$ anode, respectively. More impressive, when the current density backs to $0.1 \mathrm{~A} \mathrm{~g}^{-1}$, the capacity recovered to $467 \mathrm{~mA} \mathrm{~h} \mathrm{~g}^{-1}$, indicating that the structure of Se@HMCS composites material can withstand different current densities. As shown in Figure 6d, the energy density of Li-ion full-cell could reach $181 \mathrm{Wh} \mathrm{kg}^{-1}$ at power density of 0.02 $\mathrm{kW} \mathrm{kg}^{-1}$ total. Moreover, the Li-ion full cell exhibits a reversible capacity of $256 \mathrm{~mA} \mathrm{~h} \mathrm{~g}^{-}$ ${ }^{1}$ at the current density of $0.5 \mathrm{~A} \mathrm{~g}^{-1}$, even after 150 cycles. It is inescapably clear that the digital inset "TYUT" image of the light-emitting diode lit by the LIBs full battery. 
a

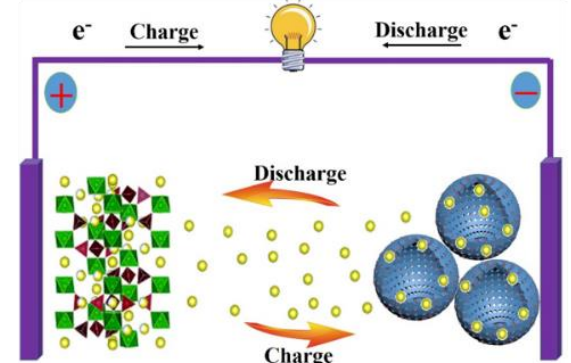

$$
\text { NVP }
$$

Cathode

c

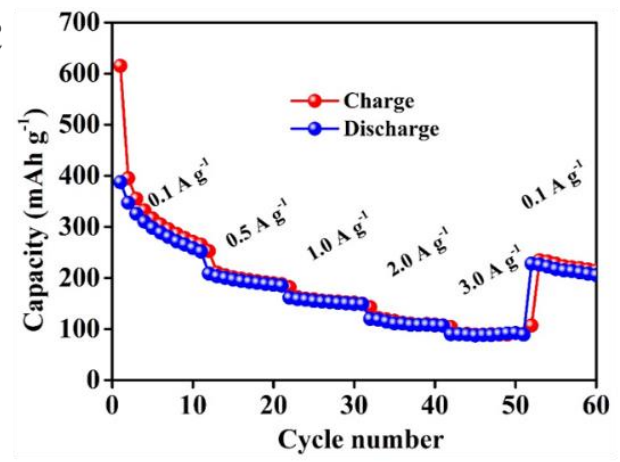

b

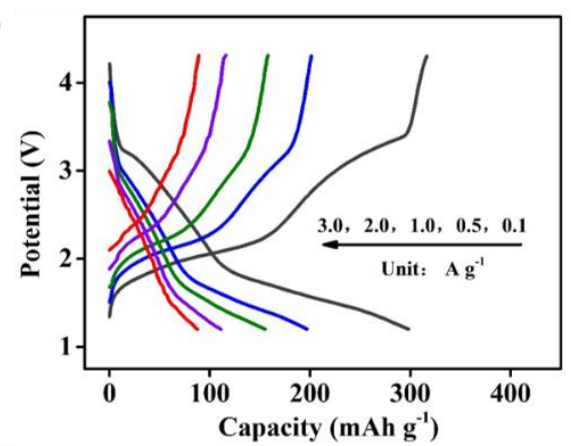

d

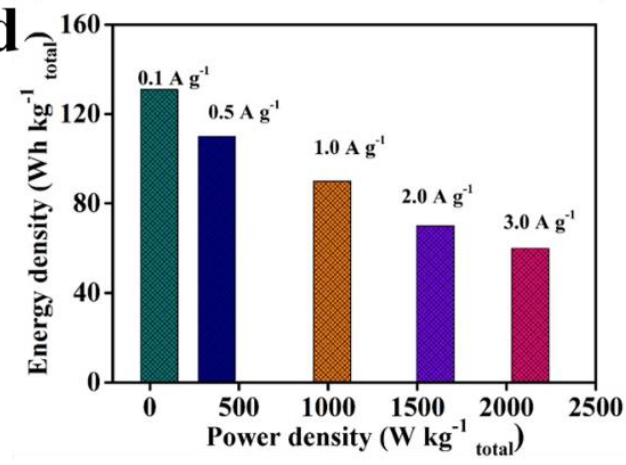

$\mathbf{e}$

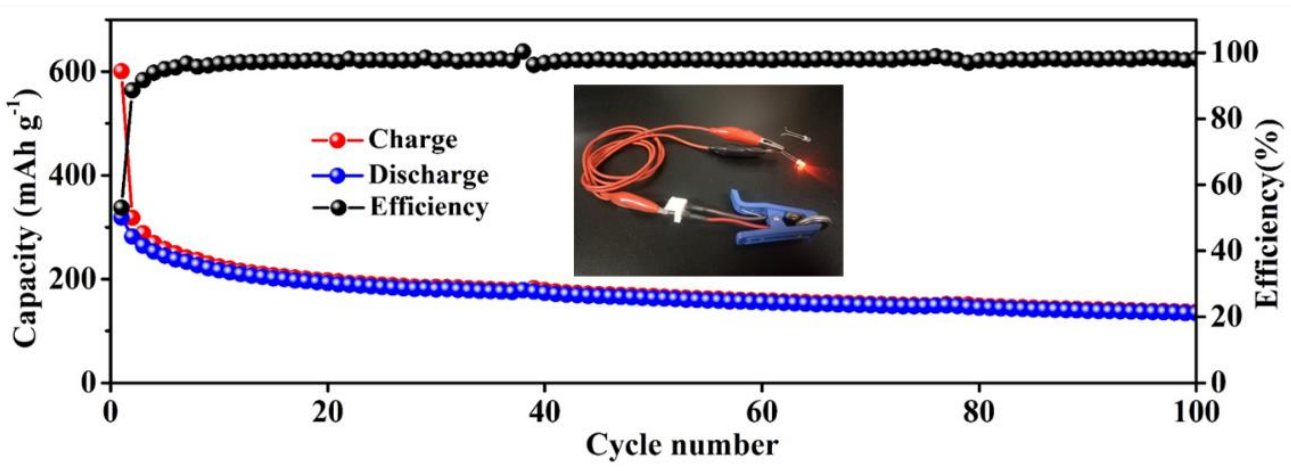

Figure 7. Se@HMCS//Na $3 \mathrm{~V}_{2}\left(\mathrm{PO}_{4}\right)_{3} / \mathrm{C}$ Na-ion full cell: (a) Schematic illustration of the full cell with $\mathrm{Se} @ \mathrm{HMCS}$ anode and $\mathrm{Na}_{3} \mathrm{~V}_{2}\left(\mathrm{PO}_{4}\right)_{3} / \mathrm{C}$ cathode. (b) Charge/discharge curves at different rates (the capacity is calculated by the mass of anode). (c) Rate performance at different rates (the capacity is calculated by the mass of anode). (d) Ragone plot of this full battery about the power and energy density (they are evaluated by the mass of total). (e) Cycling performance at $0.5 \mathrm{Ag}^{-1}$ anode (the capacity is calculated by the mass of anode and the light-emitting diode lit by the SIBs full battery).

The electrochemical performance of Na-ion full-cell was investigated and shown in Figure 7, which assembled by Se@HMCS material as anode and the home-made 
$\mathrm{Na}_{3} \mathrm{~V}_{2}\left(\mathrm{PO}_{4}\right)_{3} / \mathrm{C}$ nanocomposite $(\mathrm{NVP} / \mathrm{C})$ as the cathode (Figure S16 and Figure 7a) [38]. The NVP/C powder exhibits outstanding cycling stability and high rate capability in the half cell (Figure S17). Figure $7 \mathbf{b}$ show the electrochemical behavior of $\mathrm{Se} @ \mathrm{HMCS} / / \mathrm{Na}_{3} \mathrm{~V}_{2}\left(\mathrm{PO}_{4}\right)_{3} / \mathrm{C}$ full cell measured at different rates in the voltage range of 1.2-4.2 V. Figure 7c presented the rate capability measurements of the Na-ion full-cell at various current rates from 0.1 to $3 \mathrm{~A} \mathrm{~g}^{-1}$. It delivers high average reversible capacity of $251,208,167,127$, and $95 \mathrm{~mA} \mathrm{~h} \mathrm{~g}^{-1}$ at $0.1,0.5,1,2$, and $3 \mathrm{~A} \mathrm{~g} \mathrm{~g}^{-1}$ anode, respectively. When the current density is back to $0.1 \mathrm{~A} \mathrm{~g}^{-1}$, the reversible capacities almost recover to their initial values, once again indicating their stable structures during the cycling. At a power density of $52 \mathrm{~W} \mathrm{~kg}^{-1}$, the energy density is up to $130 \mathrm{Wh} \mathrm{kg}^{-1}$ total (Figure 7d). The Na-ion full-cell still maintains a reversible capacity of $180 \mathrm{~mA} \mathrm{~h} \mathrm{~g}^{-1}$ after 100 cycles at $0.5 \mathrm{~A} \mathrm{~g} \mathrm{~g}^{-1}$, with the $\mathrm{CE}$ almost approaching 99.9\% (Figure 7e). It can be evidently seen that the light emitting diode (LED) was emitting light when the Na-ion full cell was turned on.

\section{Conclusion}

In summary, Se@HCMS were prepared by a simple template process followed by a melt-diffusion method. The electrochemical results demonstrated Se@HCMS composite was an active and durable anode for long cycle life of LIBs/SIBs. The superior electrochemical properties are attributed to the unique hollow mesoporous carbon spheres, improving the conductivity, accommodating volumetric expansion of Se and polyselenide during long cycling. This facile and novelty strategy could be easily extended to other materials with low electronic conductivity for advanced energy 
storage systems.

\section{Acknowledgments}

The authors gratefully acknowledge the National Natural Science Foundation of China for support (Nos. 51671140 and 51301117), the Natural Science Foundation of Shanxi Province of China (201701D221077), the National Natural Foundation of China (No. 21971172), and the Australian Research Council (ARC) for support provided through a Discovery Project (DP160102627) and a Linkage Project (LP160100273).

\section{Reference}

[1] N. Yabuuchi, K. Kubota, M. Dahbi, S. Komaba, Research development on sodiumion batteries, Chem. Rev. 114 (2014) 11636-11682.

[2] M. Armand, J.M. Tarascon, Building better batteries, Nature 451 (2008) 652.

[3] J. Chen, F. Cheng, Combination of lightweight elements and nanostructured materials for batteries, Acc. Chem. Res. 42 (2009) 713-723.

[4] C.S. Yan, C. Lv, Y. Zhu, G. Chen, J.X. Sun, G.H. Yu, Engineering 2D nanofluidic Li-ion transport channels for superior electrochemical energy storage, Adv. Mater. 29 (2017) 1703909.

[5] J.W. Choi, D. Aurbach, Promise and reality of post-lithium-ion batteries with high energy densities, Nat. Rev. Mater. 1 (2016) 16013.

[6] Y. Idota, T. Kubota, A. Matsufuji, Y. Maekawa, T. Miyasaka, Tin-based amorphous oxide: a high-capacity lithium-ion-storage material, Science 276 (1997) 13951387.

[7] H.S. Li, L.L. Peng, Y. Zhu, D.H. Chen, X.G. Zhang, G.H. Yu. An advanced highenergy sodium ion full battery based on nanostructured $\mathrm{Na}_{2} \mathrm{Ti}_{3} \mathrm{O}_{7} / \mathrm{VOPO}_{4}$ layered materials. Energy Environ. Sci. 9 (2016) 3399-3405.

[8] N.N. Wang, C.X. Chu, X. Xu, Y. Du, J. Yang, Z.C. Bai, Comprehensive new insights and perspectives into Ti-based anodes for next-generation alkaline metal $\left(\mathrm{Na}^{+}, \mathrm{K}^{+}\right)$ion batteries, Adv. Energy Mater. 8 (2018) 1801888. 
[9] S.P. Ong, V.L. Chevrier, G. Hautier, A. Jain, C. Moore, S. Kim, Voltage, stability and diffusion barrier differences between sodium-ion and lithium-ion intercalation materials. Energy Environ. Sci. 4 (2011) 3680-3688.

[10] V. Palomares, P. Serras, I. Villaluenga, K. Hueso, J. Gonzalez, T. Rojo. Na-ion batteries, recent advances and present challenges to become low cost energy storage systems, Energy Environ. Sci. 5 (2012) 5884-5901.

[11] Y.H. Zhang, N.N. Wang, C. Sun, Z.X. Lu, P. Xue, B. Tang, Z.C. Bai, 3D spongy $\mathrm{CoS}_{2}$ nanoparticles/carbon composite as high-performance anode material for lithium/sodium ion batteries, Chem. Eng. J. 332 (2018) 370-376.

[12] C.P. Yang, S. Xin, Y.X. Yin, H. Ye, J. Zhang, Y.G. Guo. An advanced seleniumcarbon cathode for rechargeable lithium-selenium batteries, Angew. Chem., Int. Ed. 52 (2013) 8363-8367.

[13] L.L. Liu, Y.Y. Hou, Y.Q. Yang, M.X. Li, X.W. Wang, Y.P. Wu, A Se/C composite as cathode material for rechargeable lithium batteries with good electrochemical performance, RSC Adv. 4 (2014) 9086-9091.

[14] K. Han, Z. Liu, H.Q. Ye, F. Dai, Flexible self-standing graphene-Se@CNT composite film as a binder-free cathode for rechargeable Li-Se batteries, J. Power Sources 263 (2014) 85-89.

[15] A.Eftekhari, The rise of lithium-selenium batteries. Sustain. Energy Fuels 1 (2017) 14-29.

[16] Z. Li, J. Zhang, H. B. Wu, X. W. Lou, An improved Li-SeS 2 battery with high energy density and long cycle life Adv. Energy Mater. 7 (2017) 1700281.

[17] Z. Li, J.Zhang, Y.Lu, X. W. Lou, A pyrolyzed polyacrylonitrile/selenium disulfide composite cathode with remarkable lithium and sodium storage performances, Sci. Adv. 4 (2018) eaat1687.

[18] C.P. Yang, Y.X. Yin, Y.G. Guo, Elemental selenium for electrochemical energy storage, J. Phys. Chem. Lett. 6 (2015) 256-266.

[19] L.L. Liu, Y.Y. Hou, X.Y. Wu, S.Y. Xiao, Z. Chang, Y.Q. Yang, Y.P. Wu, Nanoporous selenium as a cathode material for rechargeable lithium-selenium batteries, Chem. commun. 49 (2013) 11515-11517. 
[20] P. Xue, N.N. Wang, Y. Wang, Y.H. Zhang, Y.L. Liu, B. Tang, Z.C. Bai, Nanoconfined $\mathrm{SnS}$ in 3D interconnected macroporous carbon as durable anodes for lithium/sodium ion batteries, Carbon 134 (2018) 222-231.

[21] Z.X. Lu, N.N. Wang, Y.H. Zhang, P. Xue, M.Q. Guo, B. Tang, Z.C. Bai, Pyrite $\mathrm{FeS}_{2} @ \mathrm{C}$ nanorods as smart cathode for sodium ion battery with ultra-long lifespan and notable rate performance from tunable pseudocapacitance, Electrochim. Acta 260 (2018) 755-761.

[22] Y. Lai, Y. Gan, Z. Zhang, W. Chen, J. Li, Metal-organic frameworks-derived mesoporous carbon for high performance lithium-selenium battery, Electrochim. Acta 146 (2014) 134-141.

[23] J.Zhou, J. Yang, Z. Xu, T. Zhang, Z. Chen, J. Wang, A high performance lithiumselenium battery using a microporous carbon confined selenium cathode and a compatible electrolyte, J. Mater. Chem. A 5 (2017) 9350-9357.

[24] J. Jin, X. Tian, N. Srikanth, L. B. Kong, K. Zhou, Advances and challenges of nanostructured electrodes for Li-Se batteries, J. Mater. Chem. A 5 (2017) 1011010126.

[25] S. Xin, L.Yu, Y. You, H.P. Cong, Y.X. Yin, X.L Du, The electrochemistry with lithium versus sodium of selenium confined to slit micropores in carbon, Nano Lett. 16 (2016) 4560-4568.

[26] L.C, Zeng, W.C. Zeng, Y. Jiang, X. Wei, W.H. Li, C.L. Yang, Y.W. Zhu, Y. Yan, A flexible porous carbon nanofibers-selenium cathode with superior electrochemical performance for both Li-Se and Na-Se batteries, Adv. Energy Mater. 5 (2015) 1401377.

[27] Y. Li, Y.S. Hu, M.M. Titirici, L. Chen, X. Huang. Hard carbon microtubes made from renewable cotton as high-performance anode material for sodium-ion batteries, Adv. Energy Mater. 6 (2016) 1600659.

[28] P.Wu, A. Zhang, L. Peng, F. Zhao, Y. Tang, Y. Zhou, G. H. Yu, Cyanogel-enabled homogeneous Sb-Ni-C ternary framework electrodes for enhanced sodium storage, ACS nano 12 (2018) 759-767.

[29] H. X. Shi, Z. Fang, X. Zhang, F. Li, Y. Tang, G. H. Yu, Double-network 
nanostructured hydrogel-derived ultrafine $\mathrm{Sn}-\mathrm{Fe}$ alloy in three-dimensional carbon framework for enhanced lithium storage, Nano lett. 18 (2018) 3193-3198.

[30] C. Luo, Y.H. Xu, Y.J. Zhu, Y.H. Liu, S.Y. Zheng, Y. Liu, C.S. Wang, Selenium@mesoporous carbon composite with superior lithium and sodium storage capacity, ACS Nano 7 (2013) 8003-8010.

[31] C. Luo, J.J. Wang, L.M. Suo, J.F. Mao, X.L. Fan, C.S. Wang, In situ formed carbon bonded and encapsulated selenium composites for Li-Se and Na-Se batteries, J. Mater. Chem. A 3 (2015) 555-561.

[32] B.B. Yuan, X.Z. Sun, L.C. Zeng, Y. Yu, Q.S. Wang, A freestanding and long-life sodium-selenium cathode by encapsulation of selenium into microporous multichannel carbon nanofibers, Small 14 (2018) 1703252.

[33] P. Xue, N.N. Wang, Z. Fang, Z.X. Lu, X. Xu, L. Wang, Z.C. Bai, Rayleighinstability-induced bismuth nanorod@nitrogen-doped carbon nanotubes as a long cycling and high rate anode for sodium-ion batteries, Nano Lett. 19 (2019) 19982004.

[34] X. Zhang, R.F. Zhao, Q.H. Wu, W.L. Li, C. Shen, L.B. Ni, H. Yan, G.W. Diao, M. Chen, Petal-like $\mathrm{MoS}_{2}$ nanosheets space-confined in hollow mesoporous carbon spheres for enhanced lithium storage performance, ACS nano 11 (2017) 84298436.

[35] X. Zhao, L. Yin, T. Zhang, M. Zhang, Z. Fang, C. Wang, Heteroatoms dual-doped hierarchical porous carbon-selenium composite for durable $\mathrm{Li}-\mathrm{Se}$ and $\mathrm{Na}-\mathrm{Se}$ batteries, Nano energy 49 (2018) 137-146.

[36] Q.X. Xu, H Liu, W.H. Du, R.M. Zhan, L.Y. Hu, S.J. Bao, C.L. Dai, F. Liu, M.W. $\mathrm{Xu}$, Metal-organic complex derived hierarchical porous carbon as host matrix for rechargeable Na-Se batteries, Electrochim. Acta 276 (2018) 21-27.

[37] Y. H. Qu, Z. Zhang, S. Jiang, X. Wang, Y. Lai, Y. Liu, Confining selenium in nitrogen-containing hierarchical porous carbon for high-rate rechargeable lithiumselenium batteries, J. Mater. Chem. A 2 (2014) 12255-12261.

[38] J. Ding, H. Zhou, H. Zhang, T. Stephenson, Z. Li, D. Karpuzov, Exceptional energy and new insight with a sodium-selenium battery based on a carbon 
nanosheet cathode and a pseudographite anode, Energy Environ. Sci. 10 (2016) 153-165.

[39] Y.Y. Wang, B.H. Hou, J.Z. Guo, Q.L. Ning, W.L. Pang, J. Wang, An ultralong lifespan and low-temperature workable sodium-ion full battery for stationary energy storage, Adv. Energy Mater. 8 (2018) 1703252.

[40] V. Augustyn, J. Come, M.A. Lowe, J.W. Kim, P.L. Taberna, S.H. Tolbert, Highrate electrochemical energy storage through $\mathrm{Li}^{+}$intercalation pseudocapacitance, Nat. Mater. 12 (2013) 518-522.

[41] N.L. Wu, S.Y. Wang, C.Y. Han, D.S. Wu, L.R. Shi, Electrochemical capacitor of magnetite in aqueous electrolytes, J. Power Sources 113 (2003) 173-178.

[42] C.J. Chen, Y.W. Wen, X.L. Hu, X.L. Ji, M.Y. Yan, L.Q. Mai, Y.H. Huang, $\mathrm{Na}^{+}$ intercalation pseudocapacitance in graphene-coupled titanium oxide enabling ultra-fast sodium storage and long-term cycling, Nat. Commun. 6 (2015) 6929.

[43] T.C. Liu, W. Pell, B. Conway, S. Roberson. Behavior of molybdenum nitrides as materials for electrochemical capacitors comparison with ruthenium oxide, J. Electrochem. Soc. 145 (1998) 1882-1888.

[44] K. Han, Z. Liu, J.M. Shen, Y.Y. Lin, F. Dai, H.Q. Ye, A free-standing and ultralonglife lithium-selenium battery cathode enabled by 3D mesoporous carbon/graphene hierarchical architecture, Adv. Funct. Mater. 25 (2015) 455-463.

[45] Q. Li, H.G. Liu, Z.P. Yao, J.P. Cheng, T.H. Li, Y. Li, Electrochemistry of selenium with sodium and lithium: kinetics and reaction mechanism, ACS Nano 10 (2016) 8788-8795.

[46] S. Xin, L. Yu, Y. You, H.P. Cong, Y.X. Yin, X.L. Du, The electrochemistry with lithium versus sodium of selenium confined to slit micropores in carbon, Nano Lett. 16 (2016) 4560-4568.

[47] A. Eftekhari, Low voltage anode materials for lithium-ion batteries, Energy Storage Mater. 7 (2017) 157-180.

[48] Y.H. Zhang, N.N. Wang, P. Xue, Y.L. Liu, B. Tang, Z.C. Bai, Co9S $8 @$ carbon nanospheres as high-performance anodes for sodium-ion battery, Chem. Eng. J. 343 (2018) 512-519. 
[49] N.N. Wang, X. Xu, T. Liao, Y. Du, Z.C. Bai, S.X. Dou. Boosting sodium storage of double-shell sodium titanate microspheres constructed from 2D ultrathin nanosheets via sulfur doping, Adv. Mater. 30 (2018) 1804157. 